\title{
(2) OPEN ACCESS \\ Visual benefit versus visual gain: what is the effect of baseline covariants in the treatment arm relative to the control arm? A pooled analysis of ANCHOR and MARINA
}

\author{
Adnan Tufail $\odot,{ }^{1}$ Philippe Margaron, ${ }^{2}$ Tadhg Guerin, ${ }^{3}$ Michael Larsen ${ }^{4}$
}

\begin{abstract}
'Medical Retina, Moorfields Eye Hospital \& Institute of Ophthalmology UCL, London, UK

${ }^{2}$ Novartis Pharma, Basel, Switzerland

${ }^{3}$ Theravance Biopharma, Dublin, Ireland

${ }^{4}$ Department of Ophthalmology, Rigshospitalet \& Faculty of Health and Medical Sciences, University of Copenhagen, Copenhagen, Denmark
\end{abstract}

Correspondence to Dr Adnan Tufail, Moorfields Eye Hospital, London, EC1V 2PD, UK; adnan.tufail@moorfields. nhs.uk

Received 11 January 2019

Revised 3 July 2019

Accepted 25 July 2019

Published Online First

27 September 2019
Check for updates

(c) Author(s) (or their employer(s)) 2020. Re-use permitted under CC BY-NC. No commercial re-use. See rights and permissions. Published by BMJ.

To cite: Tufail $A$, Margaron $P$, Guerin T, et al.

Br J Ophthalmol

2020:104:672-677.

\begin{abstract}
Background This study aimed to elucidate visual benefits of ranibizumab in patients with neovascular agerelated macular degeneration (nAMD) compared with control arms and identify factors affecting response.

Methods This is a post-hoc pooled analysis of two phase III studies, ANCHOR and MARINA, of ranibizumab for the treatment of nAMD. ANCHOR included 83 international sites. MARINA included 96 sites in the USA. Analysis included patients (control, $n=323$; ranibizumab, $\mathrm{n}=332$ ) with $\mathrm{nAMD}$ and a baseline best-corrected visual acuity (BCVA) of $\geq 35-<85$ letters.

Results Patients receiving ranibizumab achieved an adjusted mean BCVA superiority of 18.9 and 21.2 letters over 12 and 24 months, respectively, compared with control. Ranibizumab treatment, higher baseline BCVA, lower age and smaller lesion size were positively associated with the ability to achieve BCVA $>69$ letters. Patients with the highest baseline BCVA had lowest BCVA gains. Ranibizumab treatment, lower baseline BCVA, lower age and smaller lesion size were identified as significant predictors of BCVA gain from baseline at month 24 (all $p<0.0001$ ). However, the difference in mean BCVA gains at month 24 between treatment and control groups was similar for all baseline BCVA subgroups ( $\geq 35-<55$ letters, 21.9 letters; $\geq 55-<70$ letters, 25.2 letters; $\geq 70-<85$ letters, 19.3 letters). Conclusions Higher baseline BCVA is associated with lower BCVA gains but a greater likelihood of achieving good final BCVA >69 letters due to smaller gains needed to achieve response. Visual benefits, including maintenance of visual acuity (VA), final VA achieved and relative gain compared with natural disease progression, should be considered when assessing treatment response in $\mathrm{nAMD}$.
\end{abstract}

\section{INTRODUCTION}

Intravitreal injection of ranibizumab is a first-line therapy for the treatment of patients with neovascular age-related macular degeneration (nAMD). ${ }^{1-3}$ The efficacy and safety of ranibizumab in patients with nAMD was first demonstrated in the pivotal ANCHOR $^{45}$ and MARINA ${ }^{6}$ studies. Subsequently, the efficacy and safety of ranibizumab has been examined in numerous clinical studies, with a majority of patients retaining baseline vision and a significant proportion of patients achieving an improvement. $^{7-10}$ With years of clinical experience, ranibizumab continues to be evaluated in real-life clinical settings. ${ }^{11}$

Baseline best-corrected visual acuity (BCVA) is an important predictor of treatment response in patients with nAMD, as demonstrated through subanalyses of data from pivotal clinical studies wherein monthly ranibizumab treatment was evaluated. ${ }^{12} 13$ Lower baseline BCVA is associated with greater visual acuity (VA) gains on ranibizumab treatment. $^{12} 13$ Conversely, higher baseline BCVA results in greater VA loss in the absence of treatment. ${ }^{12} 13$ Monthly treatment has been increasingly replaced in clinical practice by flexible retreatment regimens, guided by individual functional and/ or anatomical criteria. ${ }^{14}$ Retrospective analyses of patients treated according to individualised treatment regimens suggest that the effects of baseline BCVA on VA outcomes are in line with monthly treatment. $^{2} 1115$ Retrospective patient care analyses indicate that in patients with higher baseline BCVA, ranibizumab treatment generally results in the highest VA scores at the study endpoint despite the lower relative VA gains compared with patients with lower baseline BCVA. ${ }^{11} 15$

These data suggest that although the improvement in BCVA from baseline (visual gain) is widely used as a measure of drug efficacy, it may not be the best measure of visual benefit to the patient. The benefit of treatment relative to the control arm for a given starting baseline VA at a given time point has not been analysed previously, and thus, the question whether the difference between treated and control patients at a given time point is independent of baseline BCVA remains to be answered.

The present study reports the results of a post hoc subgroup analysis of pooled data from the ANCHOR and MARINA studies. ${ }^{4-6}$ Patient subgroups were defined by baseline BCVA and other covariates including choroidal neovascularisation (CNV), lesion size, presence of blood or vitreous detachment at baseline and age. Patients treated with $0.5 \mathrm{mg}$ ranibizumab were compared with the study control arms to elucidate visual benefits from the treatment and how they were related to the aforementioned covariates in the treated and control arms.

\section{MATERIALS AND METHODS}

This was a post hoc pooled analysis of patient-level data from the ANCHOR (NCT00061594) and 
MARINA (NCT00056836) phase III studies of ranibizumab in patients with nAMD. ${ }^{46}$ The ANCHOR study enrolled 423 patients with predominantly classic lesions associated with nAMD, while the MARINA study enrolled 716 patients with minimally classic or occult CNV associated with AMD and with no classic CNV. ${ }^{4} 6$ Patients in both studies were $\geq 50$ years of age with BCVA of 20/40 to 20/230 (Snellen equivalent assessed using an ETDRS chart) at baseline; other inclusion criteria have been reported previously. ${ }^{46}$ Neither study excluded patients based on pre-existing cardiovascular, cerebrovascular or peripheral vascular conditions. ${ }^{46}$ Before initiation of each study, approval was obtained from institutional review boards or ethics committees at all clinical centres. Patients in each study provided written informed consent.

\section{Treatment}

In ANCHOR, patients were randomised 1:1:1 to receive monthly intravitreal injections of $0.3 \mathrm{mg}$ or $0.5 \mathrm{mg}$ ranibizumab plus sham verteporfin therapy followed by laser irradiation of the macula, or sham intravitreal injections plus active verteporfin therapy followed by laser irradiation of the macula. ${ }^{4}$ In MARINA, patients were randomised 1:1:1 to receive monthly intravitreal injections of $0.3 \mathrm{mg}$ or $0.5 \mathrm{mg}$ ranibizumab or sham; verteporfin therapy was permitted if $\mathrm{CNV}$ in the study eye became predominantly classic. ${ }^{6}$

\section{Endpoints and post hoc pooled analysis}

This post hoc analysis evaluated patient-level data from patients enrolled in the ANCHOR and MARINA studies who received either $0.5 \mathrm{mg}$ ranibizumab or control (sham or active), and had a BCVA at baseline of $\geq 35$ to $<85$ letters $(\geq 20 / 200$ to $<20 / 20$ Snellen). Analyses confirmed that benefits of ranibizumab over the controlled arms in each of the studies were similar, and therefore, the control arms were pooled for subsequent analyses presented herein. Visual benefits were defined as difference between the BCVA achieved in the pooled treatment arm and the BCVA achieved in the pooled control arm at each time point. Analysis of efficacy outcomes was performed using the last observation carried forward method for missing data.

Absolute BCVA at each time point from baseline to months 12 and 24 was analysed using a generalised estimating equation model with compound symmetry covariance structure. Parameters associated with $\mathrm{p}<0.05$ were kept in the final analysis. VA gains from baseline were analysed using additional baseline factors: baseline BCVA, presence of subretinal blood (absent or present/questionable), vitreous detachment (yes or no), lesion size (disc area (DA)) and patient age (years). VA gains were not analysed by optical coherence tomography (OCT) parameters and pigment epithelial detachment status as they were not collected for the study, baseline subfoveal fibrosis was an exclusion criteria and also could not be investigated. Lesion type was analysed however as it was highly correlated to the study, differences in outcomes could not be differentiated from study effects.

Logistic regression analysis using a backward elimination model was performed to assess if treatment arm $(0.5 \mathrm{mg}$ ranibizumab vs control), baseline BCVA, age and lesion size were predictive of patients achieving BCVA $>69$ letters over 12 and 24 months $(\mathrm{p}<0.05)$.

Pearson's correlation coefficient $(95 \%$ CI) analysis was performed for evaluating VA gains from baseline stratified by baseline BCVA ( $\geq 35$ to $<55$ letters ( $20 / 200$ to $20 / 80$ Snellen), $\geq 55$ to $<70$ letters (20/80 to $20 / 40$ Snellen) and $\geq 70$ to $<85$ letters (20/40 to 20/20 Snellen)).
Table 1 Association of baseline factors with the change in absolute BCVA between baseline and month 12 or month 24

\begin{tabular}{|c|c|c|c|}
\hline Parameter & Estimate & SE & $P$ value \\
\hline \multicolumn{4}{|l|}{ Month 12} \\
\hline Intercept & 16.4984 & 3.0543 & $<0.0001$ \\
\hline Baseline (letters) & 0.8549 & 0.0186 & $<0.0001$ \\
\hline Age (years) & -0.0939 & 0.0337 & 0.0053 \\
\hline Lesion size (DA) & -0.4527 & 0.0934 & $<0.0001$ \\
\hline Treatment (ranibizumab vs control) & 4.0367 & 0.5003 & $<0.0001$ \\
\hline Time (months) & 1.5749 & 0.5605 & 0.0050 \\
\hline Time (months)* Baseline (letters) & -0.0201 & 0.0033 & $<0.0001$ \\
\hline Time (months) ${ }^{\star}$ Age (years) & -0.0183 & 0.0063 & 0.0037 \\
\hline Time (months) ${ }^{*}$ Treatment (ranibizumab vs control) & 1.4735 & 0.0895 & $<0.0001$ \\
\hline Time (months) ${ }^{*}$ Lesion size (DA) & -0.0407 & 0.0175 & 0.0201 \\
\hline \multicolumn{4}{|l|}{ Month 24} \\
\hline Intercept & 18.6623 & 3.6461 & $<0.0001$ \\
\hline Baseline (letters) & 0.8184 & 0.0219 & $<0.0001$ \\
\hline Age (years) & -0.1217 & 0.0410 & 0.0030 \\
\hline Lesion size (DA) & -0.5110 & 0.1263 & $<0.0001$ \\
\hline Treatment (ranibizumab vs control) & 7.6340 & 0.6259 & $<0.0001$ \\
\hline Time (months) & 1.1429 & 0.2783 & $<0.0001$ \\
\hline Time (months)*Baseline (letters) & -0.0129 & 0.0018 & $<0.0001$ \\
\hline Time (months)*Age (years) & -0.0130 & 0.0032 & $<0.0001$ \\
\hline Time (months) ${ }^{*}$ Treatment (ranibizumab vs control) & 0.7610 & 0.0494 & $<0.0001$ \\
\hline Time (months) ${ }^{*}$ Lesion size (DA) & -0.0270 & 0.0102 & 0.0082 \\
\hline
\end{tabular}

* in the table indicates the interaction between two terms in the analysis model BCVA, best-corrected visual acuity; DA, disc area.

Analysis of variance or linear regression was performed on each of the baseline covariates to assess suitability for inclusion in a multiple regression model $(p<0.20)$. Selected covariates were included in a backward elimination model with treatment arm (0.5 mg ranibizumab, control), baseline BCVA and study (ANCHOR, MARINA). Multiple regression analysis was performed separately for change in BCVA from baseline to months 12 and 24. Lesion size, age and baseline BCVA were analysed as continuous variables, whereas treatment $(0.5 \mathrm{mg}$ ranibizumab, control) and study (ANCHOR, MARINA) were analysed as categorical variables.

\section{RESULTS}

From the multiple regression analysis of patient-level data of ANCHOR and MARINA, patients receiving ranibizumab had an adjusted mean BCVA superiority of 18.9 letters over 12 months and 21.2 letters over 24 months, compared with the control arm.

\section{Parameters to assess effects on absolute BCVA over time}

The analysis of absolute BCVA over time from baseline to month 12 showed that vitreous detachment or presence of subretinal blood did not impact BCVA over time once adjustment for baseline BCVA, age, baseline lesion size and treatment had been performed. Patients who were older gained approximately 0.31 fewer letter per year of age over 12 months (table 1). Patients presenting with larger lesions had a lower BCVA of at least 0.45 fewer letter for each DA increase in lesion size over 12 months, which also led to lesser gains of approximately 0.04 fewer letter per month per lesion DA (table 1). Over 12 months, visual benefits were observed in patients receiving $0.5 \mathrm{mg}$ ranibizumab, with gains increasing by approximately 1.5 letters more per month compared with the control arm (table 1). Baseline BCVA was inversely associated with increased BCVA overtime 
Table 2 Logistic regression analysis to identify parameters to predict an outcome of BCVA $>69$ letters at months 12 and 24

\begin{tabular}{|c|c|c|c|c|}
\hline Parameter & Estimate & OR & $95 \% \mathrm{Cl}$ & $P$ value \\
\hline \multicolumn{5}{|l|}{ Month 12} \\
\hline Intercept & -3.876 & & & \\
\hline $\begin{array}{l}\text { Treatment } \\
(0.5 \mathrm{mg} \text { vs } \\
\text { control) }\end{array}$ & 1.240 & 11.951 & 7.044 to 20.275 & $<0.0001$ \\
\hline $\begin{array}{l}\text { Lesion size } \\
\text { (DA) }\end{array}$ & -0.168 & 0.845 & 0.770 to 0.928 & 0.0004 \\
\hline Age (years) & -0.036 & 0.965 & 0.938 to 0.992 & 0.0110 \\
\hline $\begin{array}{l}\text { Baseline } \\
\text { BCVA } \\
\text { (letters) }\end{array}$ & 0.098 & 1.103 & 1.079 to 1.127 & $<0.0001$ \\
\hline \multicolumn{5}{|l|}{ Month 24} \\
\hline Intercept & -3.111 & & & \\
\hline $\begin{array}{l}\text { Treatment } \\
\text { ( } 0.5 \mathrm{mg} \text { vs } \\
\text { control) }\end{array}$ & 1.346 & 14.767 & 8.461 to 25.776 & $<0.0001$ \\
\hline $\begin{array}{l}\text { Lesion size } \\
\text { (DA) }\end{array}$ & -0.166 & 0.847 & 0.773 to 0.929 & 0.0004 \\
\hline Age (years) & -0.033 & 0.968 & 0.942 to 0.995 & 0.0189 \\
\hline $\begin{array}{l}\text { Baseline } \\
\text { BCVA } \\
\text { (letters) }\end{array}$ & 0.079 & 1.082 & 1.061 to 1.103 & $<0.0001$ \\
\hline
\end{tabular}

$\mathrm{BCVA}$, best-corrected visual acuity; DA, disc area.

since per one letter higher BCVA recorded at baseline, a patient gained an average of 0.02 letter less per month (table 1 ); this equates to approximately 2.4 letters less gain over 12 months for every 10 letters higher at baseline. Similar results were observed when absolute BCVA was analysed from baseline to month 24 (table 1).

\section{Parameters to predict outcome of BCVA $>69$ letters (20/40 Snellen)}

Investigation of parameters that were predictive of BCVA $>69$ letters at 12 and 24 months showed that patients in the $0.5 \mathrm{mg}$ ranibizumab arm were 12 times more likely than those in the control arm to achieve this at 12 months $(\mathrm{p}<0.0001$; table 2$)$; at month 24, this ratio increased by approximately 15 times $(\mathrm{p}<0.0001)$. Baseline BCVA was positively associated with the ability to achieve BCVA >69 letters; for every letter increase in baseline BCVA, a patient was $110 \%$ more likely to achieve BCVA $>69$ letters at 12 or 24 months ( $p<0.0001$; table 2$)$. This differs from the BCVA gain analysis, as the higher the BCVA at baseline, the smaller the gain needed to achieve a BCVA of $>69$ letters. Lesion size was negatively associated with the ability to achieve BCVA > 69 letters. Each DA increase in lesion size corresponded to the patient being $15.0 \%$ less likely $(\mathrm{OR}=0.85)$ to achieve BCVA $>69$ letters at 12 and 24 months $(\mathrm{p}=0.0004$; table 2). For example, compared with a patient with lesion size of $1 \mathrm{DA}$, a patient with lesion size of $6 \mathrm{DA}$ was $57.0 \%$ less likely to achieve BCVA $>69$ letters (20/40 Snellen) at month 12 and month 24. Age was also slightly negatively associated with the ability to achieve BCVA >69 letters (20/40 Snellen). For every year increase in age, the patient was $3.0 \%$ less likely $(\mathrm{OR}=0.97)$ to achieve BCVA $>69$ letters at both $12(\mathrm{p}=0.0110)$ and 24 months ( $p=0.0189$; table 2$)$. Thus, when compared with patients of 60 years old, a patient of 80 years old was $51.0 \%$ less likely to achieve BCVA 69 letters (20/40 Snellen) at month 12 and month 24 .
A
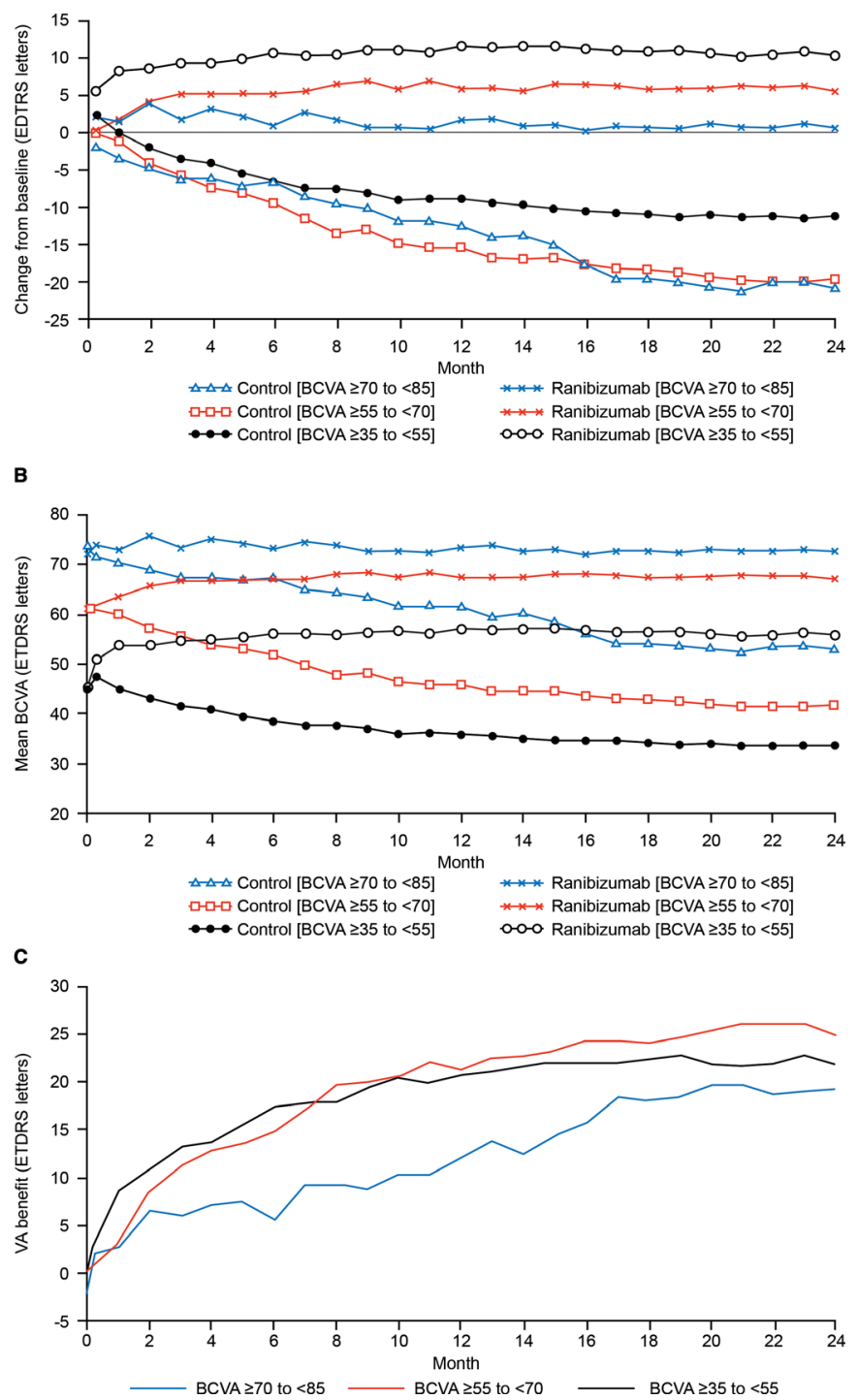

Figure 1 Assessment of visual acuity outcomes over the 24-month study period: patients stratified by baseline BCVA (pooled, LOCF). Pooled data from patients receiving $0.5 \mathrm{mg}$ ranibizumab or from the control arms (control) were analysed according to baseline BCVA and assigned to one of these three groups: $B C V A \geq 35-<55$ letters (20/200-20/80 Snellen; ranibizumab, $n=165$; control, $n=146$ ), BCVA $\geq 55-<70$ letters (20/80-20/40 Snellen; ranibizumab, $n=137$; control, $\mathrm{n}=155)$ or $\mathrm{BCVA} \geq 70-<85$ letters (20/40-20/20 Snellen; ranibizumab, $n=30$; control, $n=22$ ). Visual outcomes were assessed by (A) mean BCVA change from baseline; $(B)$ mean BCVA change over time; and (C) visual benefits over time (difference between mean BCVA in pooled $0.5 \mathrm{mg}$ ranibizumab treatment arms $(n=332)$ vs control arms $(n=323))$. BCVA, best-corrected visual acuity; LOCF, last observation carried forward; N, number of patients; VA, visual acuity.

\section{VA GAIN STRATIFIED BY BASELINE BCVA \\ Treatment arms}

Overall, change in BCVA from baseline to month 24 was dependent on baseline BCVA (figure 1A). Pearson's correlation coefficient $(95 \% \mathrm{CI})$ was $\mathrm{r}=-0.21(-0.31,-0.11)$ for patients receiving $0.5 \mathrm{mg}$ ranibizumab, $\mathrm{r}=-0.44(-0.52,-0.35)$ for those in the pooled control arm, and $r=-0.27(-0.34,-0.21)$ for all patients. In patients who received $0.5 \mathrm{mg}$ ranibizumab over the 24-month study period, gains in BCVA from baseline were observed in the 


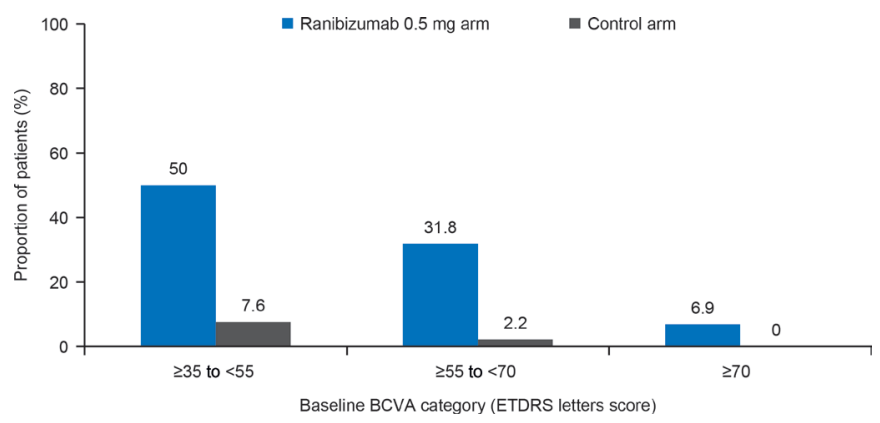

Figure 2 Proportion of patients gaining $\geq 15$ letters by baseline BCVA category at month 12 . BCVA, best-corrected visual acuity.

lowest two baseline BCVA subgroups (baseline BCVA: $\geq 35$ to $<55$, +10.3 letters; baseline $\mathrm{BCVA} \geq 55$ to $<70,+5.5$ letters), and stabilisation of BCVA was observed for patients in the baseline BCVA $\geq 70$ to $<85$ subgroups $(+0.6$ letter; figure $1 \mathrm{~A})$. The lowest gains in BCVA were observed in patients with the highest BCVA at baseline; conversely, the highest gains in BCVA were observed in those with the lowest BCVA at baseline (figure $1 \mathrm{~A}$ ). The proportion of patients gaining $\geq 15$ letters at month 12 was higher in lower baseline BCVA subgroups compared with the higher baseline BCVA subgroup (figure 2). Mean BCVA at month 24 showed a strong positive correlation with baseline BCVA in patients treated with ranibizumab $(r=0.52 ; 95 \%$ CI $0.44,0.59)$. In the two lowest BCVA subgroups, a rapid gain in BCVA was observed during the first 2-3 months, after which the average BCVA was maintained. This plateau in improved BCVA (defined as 'ceiling effect') was observed in all patient subgroups, the level of which depended on baseline BCVA (figure 1B). Thus, the three subgroups stratified by baseline BCVA plateaued at different levels at month 24 (figure 1B).

\section{Control arms}

Decline in BCVA from baseline was observed in all patient subgroups of the pooled study control arms over 24 months, and the greatest losses in BCVA were observed in patients with the highest BCVA at baseline; conversely, the smallest losses in BCVA were observed in patients with the lowest BCVA at baseline (baseline BCVA: $\geq 35$ to $<55$ letters, -11.2 letters; $\geq 55$ to $<70$ letters, -19.4 letters; $\geq 70$ to $<85$ letters, -20.5 letters; figure $1 \mathrm{~A})$. Similar to the patient subgroups receiving ranibizumab $0.5 \mathrm{mg}$, BCVA at month 24 showed a positive correlation $(r=0.35 ; 95 \%$ CI $0.25,0.43)$ with baseline BCVA: baseline BCVA $\geq 35$ to $<55$ letters, 33.9 letters; baseline BCVA $\geq 55$ to $<70$ letters, 41.9 letters; baseline BCVA $\geq 70$ to $<85$ letters, 53.2 letters (figure $1 \mathrm{~B}$ ). This analysis shows the actual change in BCVA by baseline VA category in the treatment and control arms and is not a regression to the mean effect of $0.5 \mathrm{mg}$ ranibizumab treatment arm versus control arm. Greater decline in BCVA from baseline over 24 months was observed in the control arms in all baseline VA categories compared with the ranibizumab treatment arms; however, the rate of BCVA decline in the control arms diminished over time.

\section{Treatment arm relative to control arm}

In all baseline BCVA subgroups, visual benefit of ranibizumab versus control was $\geq 19$ letters at 24 months: baseline BCVA $\geq 35$ to $<55$ letters, 21.9 letters; baseline BCVA $\geq 55$ to $<70$ letters, 25.2 letters; and baseline BCVA $\geq 70$ to $<85$ letters, 19.3 letters (figure $1 \mathrm{C}$ ). The increase in visual benefit observed over time was more rapid in the two subgroups with the lower baseline BCVA than in subgroup with higher starting baseline BCVA; however, all three subgroups showed an increasing visual benefits
Table 3 Multiple regression model for the association of baseline factors with gain in BCVA from baseline at months 12 and 24

\begin{tabular}{lll}
\hline Parameter & Estimate & P value \\
\hline Month 12 & & \\
\hline Intercept & 37.179 & $<0.0001$ \\
\hline $\begin{array}{l}\text { Treatment (0.5 mg vs } \\
\text { control) }\end{array}$ & 18.856 & $<0.0001$ \\
\hline $\begin{array}{l}\text { Study (ANCHOR vs } \\
\text { MARINA) }\end{array}$ & -3.666 & 0.0059 \\
\hline Lesion size (DA) & -1.207 & $<0.0001$ \\
\hline Baseline BCVA (letters) & -0.395 & $<0.0001$ \\
\hline Age (years) & -0.281 & $<0.0001$ \\
\hline Month 24 & & \\
\hline Intercept & 42.011 & $<0.0001$ \\
\hline $\begin{array}{l}\text { Treatment (0.5 mg vs } \\
\text { control) }\end{array}$ & 21.156 & $<0.0001$ \\
\hline Lesion size (DA) & -1.128 & $<0.0001$ \\
\hline Baseline BCVA (letters) & -0.456 & $<0.0001$ \\
\hline Age (years) & -0.363 & $<0.0001$ \\
\hline
\end{tabular}

BCVA, best-corrected visual acuity; DA, disc area

that were sustained in the long term. Additionally, the change in mean VA between treatment and control groups was comparable for all baseline BCVA subgroups at month 24 (figure 1C).

\section{Multivariate analysis}

Presence of subretinal blood and vitreous detachment were not included in the final multivariate analysis model to identify predictors of BCVA change from baseline due to lack of evidence from the univariate analysis model $(p \geq 0.20)$. Significant predictors of the change in BCVA from baseline to month 12 were treatment arm, study, lesion size, baseline BCV and patient age (all $\mathrm{p}<0.0001$ except for study; table 3). Treatment arm, lesion size, baseline BCVA and age (but not study) were also identified as significant predictors of the change in BCVA from baseline to month 24 (all $\mathrm{p}<0.0001$; table 3).

\section{DISCUSSION}

This post hoc subgroup analysis of pooled data from the ANCHOR and MARINA studies showed that ranibizumab treatment resulted in substantial vision improvement over 24 months versus control, with treatment arm, baseline BCVA, age and lesion size being identified as significant predictors (all $\mathrm{p}<0.0001$ ) of change in BCVA from baseline at month 24 .

In the present analysis, baseline BCVA was inversely associated with change in BCVA over 24 months. The higher the baseline BCVA, the lesser was the VA gain per month over 24 months and vice versa, indicating that baseline BCVA is one of the strong predictors of VA gains. These results are consistent with the other long-term studies of ranibizumab. ${ }^{11-18}$ Ranibizumab treatment over 24 months has generally resulted in preservation of vision versus baseline in a majority of patients with nAMD, although decline of VA over time may be inevitable, reflecting natural progression of the disease. ${ }^{16-19}$ Thus, maintenance of good VA, rather than focusing only on VA gains over years of treatment, should be considered while examining the post-treatment visual status in patients with nAMD. ${ }^{18}$

By subdividing patient groups into three strata based on baseline BCVA, this study has shown that VA gains relative to baseline BCVA in the ranibizumab arms of the ANCHOR and MARINA studies were higher in patients with lower baseline BCVA, while 
smaller vision improvements were seen in patients with higher baseline BCVA (figure 1A). Additionally, an initial rapid VA gain was observed in all patient subgroups, which was maintained over 24 months (figure 1B). This is clear evidence of a 'ceiling effect' observed in patients with nAMD, the extent of which depends on baseline BCVA. Similar effect with anti-vascular endothelial growth factor (anti-VEGF) therapy has been reported in a national nAMD database study from the UK $(\mathrm{N}=11135),{ }^{11}$ a retrospective study from Denmark $(\mathrm{N}=555)^{17}$ and the prospective MONT BLANC study $(\mathrm{N}=255) .{ }^{20}$ The present study has the added virtue of including data from control arms; therefore, it presents a much clearer picture of outcomes of anti-VEGF therapy in nAMD by showing that the relative benefit after 24 months of treatment is nearly the same (approximately 20 letters) and is independent of baseline BCVA (figure 1C). This also shows that the actual change in BCVA by baseline VA category is not just a regression to the mean effect of ranibizumab treatment arm versus control arm but the decline in BCVA from baseline over 24 months was higher in the control arms in all baseline VA categories; especially, the greatest losses in BCVA were observed in patients with the highest BCVA at baseline. Thus, patients with higher BCVA have shown a greater likelihood of visual loss over time, if left untreated. ${ }^{14} 2122$ In fact, timely initiation of ranibizumab treatment in patients with nAMD has proved to be beneficial in a substantial improvement in vision ${ }^{46}$ and has reported better VA outcomes in patients with good baseline VA than those with lower baseline VA. ${ }^{23}$ Of note, that ANCHOR had an active control arm that we know from the verteporfin photodynamic therapy (VPDT trials that vPDT treatment slows down the mean decline in vision relative to a no-treatment control group. Therefore, pooling the MARINA untreated control arm and the actively treated control arm with vPDT may underestimate the benefits of treatment versus the pooled control arm. These observations are important for the clinicians' ability to interpret the course of disease progression and titrate retreatment of individual patients based on flexible treatment regimen, which has become the standard of care in several countries.

Studies have shown that the early treatment with anti-VEGF increases the possibility of improvement or preservation of vision over time in patients with nAMD. ${ }^{14} 18192122{ }^{24}$ Better visual outcomes are usually associated with lower age of the patients at baseline. ${ }^{141819212224}$ Consistent with findings from these studies, this analysis also emphasises the importance of early treatment after a confirmed diagnosis of nAMD; patient's age was also inversely correlated with the ability to achieve BCVA $>69$ letters (table 2). Thus, younger patients with nAMD were more likely to achieve good visual outcomes.

Another baseline characteristic that may be associated with visual outcomes is $\mathrm{CNV}$ lesion size. Consistent with previous clinical findings, the present analysis also demonstrated that larger lesion size (CNV area) at baseline usually results in less improvement in vision. ${ }^{14} 1822$

Anti-VEGFs have been the standard of care for the treatment of nAMD since the approval of ranibizumab in 2006. ${ }^{12}$ Ranibizumab has robust clinical evidence demonstrating its efficacy and safety profile through numerous randomised controlled trials. ${ }^{4} 625-27$ Monthly treatment with ranibizumab has resulted in the most favourable visual outcomes. ${ }^{462829}$ However, due to variability in patients' retreatment needs, flexible and/or tailored treatment regimens are being extensively used by clinicians worldwide. ${ }^{17} 1930-33$ Reportedly, the successful maintenance of VA gains is partly correlated to the injection frequency ${ }^{19435}$; and the possibility of undertreatment with the flexible approach cannot be ruled out. ${ }^{2627}$ The monthly treatment regimen allows unbiased evaluation of treatment outcomes, and hence, this pooled analysis evaluated the effects of baseline covariates in the monthly treatment arm versus the control arm to assess visual outcomes over 24 months from the ANCHOR and MARINA studies. Similar post hoc evaluation of clinical study findings and related drug efficacy can be helpful in future to make treatment decisions for patients with nAMD, in whom visual loss is primarily related to unavoidable disease progression.

This post hoc analysis was undertaken to address the idea that good and bad responses or even non-response to intravitreal antiVEGF therapy can be defined in clinical practice and retrospective analyses of non-randomised interventions. ${ }^{2}$ While differences in treatment outcome can be defined, the definition of good, bad or absent response is not meaningful without a control group. We therefore took recourse to an analysis of the best available clinical data from studies (ANCHOR and MARINA) that included untreated controls or a vastly inferior alternative (verteporfin). While the analysis expanded the set of baseline predictors of treatment outcome, it did not identify any way of prospectively defining a subgroup of patients with an unfavourable outcome. We conclude that a comparatively poor outcome cannot meaningfully be said to be a poor response to therapy because it should be compared with the poorest outcomes in the control group. While a poor outcome can be defined at the end of the course of treatment, the only potential use thereof is for decisions about future therapy. Such use is made difficult by a lack of studies that randomise patients to different treatment regimens from a time point after initial injection based on the individual patient's summarised treatment response. There are studies, however, that have tested adaptive strategies, notably treat-and-extend-regimens, where the decision to reinject or not to reinject is based on disease activity on the very day of the visit. Such studies have shown non-inferior outcomes of individualised treatment compared with fixed regimens, ${ }^{3637}$ thus supporting that disease activity determines the course of disease, but that still does not enable assessment of response, that is, the extent to which a given patient did benefit from treatment compared with no treatment. There is a fundamental difficulty in assessing the treatment response of a single patient, but even for groups it is difficult to assess the response to interventions such as drug switching without using a randomised study design. ${ }^{38}$

The study was limited by restricted anatomical data, lack of data on patients with baseline BCVA $<35$ letters and inclusion of treatment-naïve patients only. However, this post hoc analysis fulfilled a range of criteria for $\mathrm{CNV}$ activity to analyse ranibizumab treatment versus control by patient subgroups and other baseline covariates.

To conclude, baseline BCVA had the most significant effect on visual outcomes in our study. Patients with lower baseline BCVA achieved the maximum gains from baseline, but those with higher baseline BCVA achieved the highest final BCVA due to smaller gains needed to achieve this response. This analysis also indicated that ranibizumab treatment, higher baseline BCVA, lower age and smaller lesion size were positively correlated with the ability to achieve better visual outcomes. However, the VA superiority with ranibizumab treatment over natural disease progression was similar for each of the three starting VA groups by 24 months. Visual benefits, including maintenance of VA, final VA achieved and relative gain compared with natural disease progression or best care, should be considered when assessing treatment response in nAMD.

Acknowledgements Novartis designed and sponsored the initial MARINA and ANCHOR studies and performed statistical analysis of these data. The authors TG and PM were employees of Novartis at the time of manuscript development. TG had full access to all study data and takes responsibility for integrity of the data and 
accuracy of the data analysis. All other authors were involved in interpretation of the data, preparation, review and approval of the manuscript, and the decision to submit the manuscript for publication. The authors thank Fishawack Communications, UK and Urvashi Bawane (Scientific Services Practice - Product Lifecycle Services, Novartis Healthcare Pvt., Hyderabad, India) for their medical writing and editorial assistance towards the development of this manuscript.

Contributors AT, PM, TG and ML were involved in the interpretation of the data, preparation, review and approval of the manuscript, as well as in the decision to submit the manuscript for publication. TG had full access to all of the data in the study and takes responsibility for the integrity and accuracy of the data analysis.

Funding Dr Tufail has received a proportion of his funding from the Department of Health's NIHR Biomedical Research Centre for Ophthalmology at Moorfields Eye Hospital and UCL Institute of Ophthalmology. The views expressed in the publication are those of the author and not necessarily those of the Department of Health.

Competing interests AT: consultant for Allergan, Bayer, Genentech, Heidelberg Engineering, Novartis, Roche and received grant support from Novartis. ML: received lecture fees and the Rigshospitalet center has received compensation for the conduct of clinical trials from Allergan, Alcon, Novartis; Novo Nordisk, AbbVie and Roche. TG: employee of Novartis Ireland Limited, Dublin, Ireland during manuscript development and currently employed with Theravance Biopharma US, South San Francisco, CA. PM: employee of Novartis Pharma AG, Basel, Switzerland.

Patient consent for publication Not required.

Provenance and peer review Not commissioned; externally peer reviewed.

Data availability statement Data are available on request.

Open access This is an open access article distributed in accordance with the Creative Commons Attribution Non Commercial (CC BY-NC 4.0) license, which permits others to distribute, remix, adapt, build upon this work non-commercially, and license their derivative works on different terms, provided the original work is properly cited, appropriate credit is given, any changes made indicated, and the use is non-commercial. See: http://creativecommons.org/licenses/by-nc/4.0/.

\section{ORCID iD}

Adnan Tufail http://orcid.org/0000-0002-0965-4890

\section{REFERENCES}

1 Cohen SY, Mimoun G, Oubraham H, et al. Changes in visual acuity in patients with wet age-related macular degeneration treated with intravitreal ranibizumab in daily clinical practice: the LUMIERE study. Retina 2013;33:474-81.

2 Menghini M, Kurz-Levin MM, Amstutz C, et al. Response to ranibizumab therapy in neovascular AMD - an evaluation of good and bad responders. Klin Monbl Augenheilkd 2010;227:244-8

3 Dhoot DS, Kaiser PK. Ranibizumab for age-related macular degeneration. Expert Opin Biol Ther 2012;12:371-81.

4 Brown DM, Kaiser PK, Michels M, et al. Ranibizumab versus verteporfin for neovascular age-related macular degeneration. N Eng/ J Med 2006;355:1432-44.

5 Brown DM, Michels M, Kaiser PK, et al. Ranibizumab versus verteporfin photodynamic therapy for neovascular age-related macular degeneration: two-year results of the anchor study. Ophthalmology 2009;116:e55:57-65.

6 Rosenfeld PJ, Brown DM, Heier JS, et al. Ranibizumab for neovascular age-related macular degeneration. N Engl J Med 2006;355:1419-31.

7 Mitchell P, Bandello F, Schmidt-Erfurth U, et al. The restore study: ranibizumab monotherapy or combined with laser versus laser monotherapy for diabetic macular edema. Ophthalmology 2011;118:615-25.

8 Wolf S, Balciuniene VJ, Laganovska G, et al. Radiance: a randomized controlled study of ranibizumab in patients with choroidal neovascularization secondary to pathologic myopia. Ophthalmology 2014;121:e682:682-92.

9 Campochiaro PA, Sophie R, Pearlman J, et al. Long-Term outcomes in patients with retinal vein occlusion treated with ranibizumab: the retain study. Ophthalmology 2014;121:209-19.

10 Ho AC, Busbee BG, Regillo CD, et al. Twenty-four-month efficacy and safety of $0.5 \mathrm{Mg}$ or $2.0 \mathrm{Mg}$ ranibizumab in patients with subfoveal neovascular age-related macular degeneration. Ophthalmology 2014;121:2181-92.

11 Writing Committee for the UK Age-Related Macular Degeneration EMR Users Group. The neovascular age-related macular degeneration database: multicenter study of 92976 ranibizumab injections: report 1: visual acuity. Ophthalmology 2014;121:1092-101.

12 Boyer DS, Antoszyk AN, Awh CC, et al. Subgroup analysis of the marina study of ranibizumab in neovascular age-related macular degeneration. Ophthalmology 2007:114:246-52.

13 Kaiser PK, Brown DM, Zhang K, et al. Ranibizumab for predominantly classic neovascular age-related macular degeneration: subgroup analysis of first-year anchor results. Am J Ophthalmol 2007;144:850-7.
14 Bloch SB, la Cour M, Sander B, et al. Predictors of 1-year visual outcome in neovascular age-related macular degeneration following intravitreal ranibizumab treatment. Acta Ophthalmol 2013;91:42-7.

15 Shona O, Gupta B, Vemala R, et al. Visual acuity outcomes in ranibizumab-treated neovascular age-related macular degeneration; stratified by baseline vision. Clin Experiment Ophthalmol 2011;355:no-8.

16 Muniraju R, Ramu J, Sivaprasad S. Three-Year visual outcome and injection frequency of intravitreal ranibizumab therapy for neovascular age-related macular degeneration. Ophthalmologica 2013;230:27-33.

17 Rasmussen A, Bloch SB, Fuchs J, et al. A 4-year longitudinal study of 555 patients treated with ranibizumab for neovascular age-related macular degeneration. Ophthalmology 2013;120:2630-6.

18 Rasmussen A, Sander B. Long-Term longitudinal study of patients treated with ranibizumab for neovascular age-related macular degeneration. Curr Opin Ophthalmol 2014:25:158-63.

19 Singer MA, Awh CC, Sadda S, et al. Horizon: an open-label extension trial of ranibizumab for choroidal neovascularization secondary to age-related macular degeneration. Ophthalmology 2012;119:1175-83.

20 Larsen M, Schmidt-Erfurth U, Lanzetta P, et al. Verteporfin plus ranibizumab for choroidal neovascularization in age-related macular degeneration: twelve-month Mont blanc study results. Ophthalmology 2012;119:992-1000.

21 Rosenfeld PJ, Shapiro H, Tuomi L, et al. Characteristics of patients losing vision after 2 years of monthly dosing in the phase III ranibizumab clinical trials. Ophthalmology 2011;118:523-30.

22 Ying G-shuang, Huang J, Maguire MG, et al. Baseline predictors for one-year visual outcomes with ranibizumab or bevacizumab for neovascular age-related macular degeneration. Ophthalmology 2013;120:122-9.

23 Lee AY, Lee CS, Butt T, et al. Uk AMD EMR users group report V: benefits of initiating ranibizumab therapy for neovascular AMD in eyes with vision better than 6/12. Br J Ophthalmol 2015;99:1045-50.

24 Buitendijk GHS, Rochtchina E, Myers C, et al. Prediction of age-related macular degeneration in the general population: the three continent AMD Consortium. Ophthalmology 2013;120:2644-55.

25 Martin DF, Maguire MG, Ying G-shuang, et al. Ranibizumab and bevacizumab for neovascular age-related macular degeneration. N Engl J Med 2011;364:1897-908.

26 Regillo CD, Brown DM, Abraham P, et al. Randomized, double-masked, shamcontrolled trial of ranibizumab for neovascular age-related macular degeneration: PIER study year 1. Am J Ophthalmol 2008;145:239-48.

27 Schmidt-Erfurth U, Eldem B, Guymer R, et al. Efficacy and safety of monthly versus quarterly ranibizumab treatment in neovascular age-related macular degeneration: the excite study. Ophthalmology 2011:118:831-9.

28 Abraham P, Yue H, Wilson L. Randomized, double-masked, sham-controlled trial of ranibizumab for neovascular age-related macular degeneration: PIER study year 2. Am J Ophthalmol 2010;150:e311:315-24.

29 Martin DF, Maguire MG, Fine SL, et al. Ranibizumab and bevacizumab for treatment of neovascular age-related macular degeneration: two-year results. Ophthalmology 2012;119:1388-98.

30 Arias L, Roman I, Masuet-Aumatell C, et al. One-Year results of a flexible regimen with ranibizumab therapy in macular degeneration: relationship with the number of injections. Retina 2011;31:1261-7.

31 Fung AE, Lalwani GA, Rosenfeld PJ, et al. An optical coherence tomographyguided, variable dosing regimen with intravitreal ranibizumab (Lucentis) for neovascular age-related macular degeneration. Am J Ophthalmol 2007:143:566-83.

32 Lalwani GA, Rosenfeld PJ, Fung AE, et al. A variable-dosing regimen with intravitreal ranibizumab for neovascular age-related macular degeneration: year 2 of the PrONTO study. Am J Ophthalmol 2009;148:e41:43-58.

33 Silva R, Axer-Siegel R, Eldem B, et al. The secure study: long-term safety of ranibizumab $0.5 \mathrm{Mg}$ in neovascular age-related macular degeneration. Ophthalmology 2013;120:130-9.

34 Bhisitkul RB, Mendes TS, Rofagha S, et al. Macular atrophy progression and 7-year vision outcomes in subjects from the anchor, marina, and horizon studies: the sevenup study. Am J Ophthalmol 2015:159:e912:915-24.

35 Holz FG, Tadayoni R, Beatty S, et al. Multi-country real-life experience of anti-vascular endothelial growth factor therapy for wet age-related macular degeneration. $\mathrm{Br} J$ Ophthalmol 2015;99:220-6.

36 Silva R, Berta A, Larsen M, et al. Treat-and-Extend versus monthly regimen in neovascular age-related macular degeneration: results with ranibizumab from the trend study. Ophthalmology 2018;125:57-65.

37 Wykoff CC, Croft DE, Brown DM, et al. Prospective trial of Treat-and-Extend versus monthly dosing for neovascular age-related macular degeneration: TREX-AMD 1-year results. Ophthalmology 2015;122:2514-22.

38 Ferris FL. Evaluating effects of switching anti-vascular endothelial growth factor drugs for age-related macular degeneration and diabetic macular edema. JAMA Ophthalmol 2016. 